\title{
Leitura feminista da história das mulheres no Brasil
}

\author{
Nova História das Mulheres no \\ Brasil.
}

PINSKY, Carla Bassanezi; PEDRO, Joana Maria.

São Paulo: Contexto, 2012, 555p.

Instigante e, sem sombra de dúvida, ousada, a obra Uma Nova História das Mulheres no Brasil, publicada recentemente, contempla uma pluralidade de assuntos atualizados para o século XXI e uma série de questionamentos sobre os engajamentos políticos, com temas inovadores e poucos discutidos pelo campo da História e áreas afins. Sob a coordenação de Joana Maria de Pedro e Carla Bassanezi Pinsky, os 22 ensaios que a compõem abordam variados aspectos das conquistas femininas atuais, apresentando mudanças e permanências, recorrendo, por vezes, aos fins do século XIX.

O livro conta com especialistas consagradas na área de gênero e estudos das mulheres no Brasil. As temáticas, recorrentes entre os textos, consistem na problematização dos arranjos familiares, educação, trabalho, escola, corpo, beleza, sexualidade, cultura, política, imigração, direito, violência de gênero e formas de lazer. Aborda questões éticas e polêmicas relacionadas à eutanásia, ao aborto e à contracepção. Outros temas são ressaltados, como a atuação das muIheres na imprensa feminina e como as que participaram ativamente em guerras; discursos que são perpassados por imagens e representações do feminino em função dos modelos rígidos até os mais flexíveis, sendo inegável a contribuição que baliza a produção da crítica historiográfica referente à história das mulheres no corrente século.

Os artigos foram escritos com leveza sobre temas complexos, abordando problemáticas caras às conquistas das mulheres, de modo que podem ser lidos isolados ou de forma sequencial. Destinam-se aos/às estudantes, professores/as, pesquisadores/as das áreas de História e Ciências Sociais, jornalistas, profissionais das áreas do Direito, da Saúde Pública, àqueles/as que investem em políticas públicas, ativistas, militantes de movimentos sociais, feministas e ONGs, os quais encontram em suas linhas alicerces para executar suas demandas e podem adquirir subsídios para desenvolver com mais qualidade o seu trabalho, 
de forma crítica e exequível, pois a obra atende a todos os públicos.

Os temas oriundos das reflexões contidas nesse livro trazem, para a ordem do dia, várias modificações nas legislações civis e penais sobre família, aborto e divórcio, decorrentes das transformações pelas quais passou o país em termos urbanísticos, higienistas e de ordem moral. Mudanças essas que faziam eco às campanhas por modernização que já vinham ocorrendo desde os fins do século XIX. De acordo com Ana Silvia Scott, à medida que o século XX seguia o seu curso, foi requerido o modelo de uma "nova família", cuja protagonisła, a mãe, teria sido responsável por dispensar especial atenção ao cuidado e à educação dos filhos, responsabilizando-se pela formação moral das crianças no interior dos lares. Os espaços públicos teriam sido reservados aos homens, vistos como provedores e chefes da família. A autora destaca as mudanças ocorridas na legislação brasileira quanto à formação de novos arranjos familiares, desatualizando a ideia de família nuclear, constituída somente pelo pai, mãe e filhos. Mostra como outras formas de relacionamentos afetivos têm sido reconhecidos pelo Supremo Tribunal da Justiça, como as uniões homoafetivas e a permissão para esses casais adotarem crianças.

Com base em relatos de viajantes do final do século XIX, a historiadora June E. Hahner retoma o tema da família, pontuando os sentidos de honra e da distinção constitutivos de modelos pautados no feminino. A honra das senhoras de elite era baseada em sinais de pureza e recato, que, por sua vez, permanecia ligada à honra familiar e à hierarquia social. Hahner pondera que muitas delas desempenhavam importantes papéis na sociedade patriarcal. Apesar do poder dos maridos dentro dos lares, viúvas de fazendeiros, no interior da província de Minas Gerais, costumavam gerir sozinhas suas fazendas e escravos, assumindo o papel e o fardo de seus maridos em todos os aspectos. Mulheres da alta sociedade teriam desempenhado um papel ativo durante o movimento abolicionista, ajudando a angariar fundos para escravos libertos. Na segunda metade do século XIX, o aumento da urbanização, das exportações e da industrialização criou uma economia mais diversificada, e teria sido nesse contexto que crescera o letramento entre as mulheres. Essa configuração possibilitou que algumas delas exercessem uma grande influência nos assuntos culturais, econômicos e políticos da família, bem como na luta pela educação e pelo direito ao voto.
Trajetórias femininas relacionadas a trabalho, escola e lazer são abordadas por Silvia Fávero Arend. Essa autora mostra como foram elaboradas regras morais e de comportamento para meninas e jovens mulheres, num contexto de desigualdades que se desencadeou até o século XX. A divisão sexual do trabalho, brincadeiras de crianças, socialização dos papéis para homens e mulheres, casamento, regras de etiquetas, noções de elegância teriam sido assuntos de pauta de médicos, pedagogos, psicólogos e moralistas. A partir de análises bastante consistentes, Arend contextualiza a emergência de leis, como o Estatuto da Criança e do Adolescente, em 1990. Ela reitera ainda suas preocupações com os sentidos que a Psicologia e, sobretudo, o ponto de vista jurídico passaram a perceber acerca da adolescência e, em especial, a conotação que se dá à experiência de "ser menina".

Com diferentes visões e sob um ponto de vista inovador, a socióloga Alda Britto da Motta traz a temática das mulheres velhas, entrecruzando a história e a memória. A autora ressalta as mudanças políticas decorrentes das ditaduras no Brasil, por meio das quais as mulheres aparecem em luta pela anistia de seus familiares, então presos políticos ou exilados. Atualmente, mulheres da classe média que têm pensões, aposentadorias, e que dispõem de tempo livre, desfrutam das atividades que são designadas para a "terceira idade". Para elas são oferecidos serviços específicos de viagens, festas, congressos, cursos, grupos de convivência e universidades, galgando, assim, a uma categoria social dentro do mercado consumidor. Além disso, são vistas como "idosas jovens", em razão dos avanços da ciência - medicina e saúde pública.

As técnicas de beleza e de rejuvenescimento não têm sido alvos da atenção somente das idosas. Denise Bernuzzi de Sant'Anna traça os caminhos percorridos pelos cuidados de si e embelezamento, aliados às técnicas modernas do século XX. É contemplada aqui a historicidade em torno do corpo segundo as normas médicas e os códigos de elegância, indicando como cada época designa certos conceitos acerca do corpo, a começar de quando a beleza física era vista como uma dádiva divina na primeira metade do século XX. Atualmente, cirurgias plásticas, preenchimento facial, rejuvenescimento por laser, branqueamento, aliados à indústria da moda, regimes e meditação têm corroborado para reforçar o modelo "beleza-magreza-juventude". Desse modo, o século XXI é anunciado como a era do culto ao corpo em toda a sua dimensão orgânica, estética, física, tonando-se 
impossível o seu enquadramento em uma rede de significação única.

Neste último século, houve vários avanços, inclusive no campo da profissionalização das mulheres, embora haja muito a ser feito. Dentro do contexto da vida moderna, o trabalho feminino no mercado reprodutivo é visto como um espaço conquistado pelas mulheres, fomentado pela crescente urbanização, industrialização e imigração. Tema esse abordado por Maria Izilda Matos e Andrea Borelli, as quais demostram de forma crítica as ambiguidades e os percalços, indicando como o trabalho feminino foi considerado, por muito tempo, como uma atividade complementar ao trabalho exercido pelo chamado chefe de família. Frente às lutas como greves e manifestações por melhores salários, bem como por condições de trabalho, muitas mulheres questionaram a legislação trabalhista, denunciando os abusos, lutando por equiparação salarial e maiores possibilidades de ascensão nas carreiras, reivindicando a criação de creches.

Raquel de Barros Miguel e Carmen Ria discutem como o lazer feminino é uma prática social, indicando as normas reguladoras que ditam como as mulheres devem ocupar o seu tempo, ligado às funções de mãe, esposa e dona de casa. Distintas formas de lazer no tempo são citadas, desde o entretenimento das fotonovelas, livros, novelas, até os passeios esportivos que as mulheres fazem, atualmente, com os filhos, etc. O consumo e os cuidados com a aparência são vistos como outros requisitos imprescindíveis pelo círculo feminino dentro do ponto de vista do lazer. Imigrantes que chegam ao Brasil e as brasileiras que emigram são retratados por Maria Sílvia Bassanezi. A autora cartografa um país marcado por uma ampla diversidade ética $e$ classe social, por uma acentuada clandestinidade e pela multiplicidade de relações que os imigrantes estabelecem entre o local de destino e o de origem. Eram mulheres trazidas da Europa que atuavam no mundo da prostituição em terras brasileiras nas décadas finais do século XIX e nas primeiras do século XX. Entre as várias formas de migração, a autora destaca a presença de algumas jovens pobres que adentraram no ofício como forma de sobrevivência, após serem enganadas por homens ligados ao tráfico internacional de mulheres. Denuncia outras formas de migrações em direção às fazendas cafeeiras, aos núcleos coloniais ou às cidades. Outro movimento desta natureza é o de brasileiras envolvidas no turismo sexual fora do país.
Tema inovador é a participação feminina na arena política brasileira, conferindo legitimidade e visibilidade às atividades intelectuais e políticas das mulheres. Maria Ligia Prado e Stella Scatena Franco ponderam sobre a atuação de mulheres em projetos a partir final do século XIX. Nomes como Nísia Floresta - que lutou pelo reconhecimento da capacitação intelectual das mulheres e pelo direito à educação, sendo considerada por muitos a primeira feminista brasileira-ganham relevo na obra dessas autoras. Igualmente, outras aparecem como protagonistas de lutas que abriram caminhos para as conquistas dos séculos que se seguiram.

A luta feminina pela conquista do espaço público foi abordada por Rachel Soihet. Feministas pioneiras, como Bertha Lutz, na primeira metade do século $X X$, contribuíram para a participação das mulheres como membros ativos da sociedade, conferindo êxito às reinvindicações sufragistas e educacionais. Enfoque desafiador é o que traz Joana Maria Pedro, inquirindo o/a leitor/ a a posicionar-se frente às demandas feministas que balizaram a produção de imagens em torno do corpo, trabalho e prazer. Com amplo poder de argumentação, a autora nos instiga a pensar acerca de posturas que tomamos, por vezes, frente à discriminação sexual e à violência de gênero, posturas essas que referendam os sentidos que normalmente são atribuídos à nomenclatura "ser feminista".

No tocante à legislação, láris Ramalho Cortês contextualiza a emergência e as mudanças referentes às leis civis, penais e trabalhistas, demonstrando como foram significativas no sistema jurídico nos últimos 100 anos. Um exemplo notável é a Lei Maria da Penha, que visa combater a violência doméstica, sexual, psicológica, patrimonial e moral. De acordo com a advogada, ainda faltam garantias maiores para o cumprimento de leis existentes, como políticas que viabilizem a participação das mulheres na vida pública.

A violência de gênero aparece no artigo de Lana Lage e Maria Beatriz Nader, as quais demonstram com rigor as transformações concernentes à opinião pública e jurídica com relação à violência contra mulheres, a partir de casos que estamparam manchetes e comoveram o país ao longo de 112 anos. O artigo denuncia como muitas autoridades jurídicas, ainda hoje, desconsideram os casos de violência contra mulheres, como uma banalização de brigas entre casais, ao mesmo tempo que chama a atenção para as mudanças históricas nas quais a violência de gênero não será mais aceita em nossa sociedade. 
Discussões extremamente produtivas e polêmicas sobre a contracepção e o aborto são abordadas pela antropóloga Debora Diniz. A luta pela garantia às mulheres ao direito ao aborto continua abrindo novas perspectivas para a própria história da sexualidade feminina. Lançando mão de dados reveladores de um marco político em favor dos direitos reprodutivos das mulheres no mundo, Diniz afirma que ainda hoje o entrecruzamento do aborto, contracepção e parto é indicativo de morte de muitas mulheres no país.

Fúlvia Rosemberg reconstitui o processo da educação das mulheres no Brasil e o papel que elas desempenharam nesse terreno. Os dados encontrados aqui permitem identificar como, cada vez mais, as mulheres têm se desinteressado por carreiras no âmbito do magistério, optando por áreas do conhecimento até então monopolizadas pelos homens. A história das mulheres negras ganha um capítulo especial na pena de Bebel Nepomuceno, que contempla as dimensões do trabalho, educação, chefia de família, mobilização e visibilidade com destaque para o protagonismo exercido por elas ao longo da história. Apesar de algumas conquistas, muitas delas vêm enfrentando até hoje formas de exclusão e desigualdades, provocando mudanças relevantes na agenda social dos governantes.

Outro tema abordado são as formas de resistência e sobrevivência com as quais muitas escravas tiveram que se deparar ao longo do século XIX. Maria Odila Dias mostra como elas enfrentaram a opressão racial, o preconceito e a violência de gênero, tanto da parte de seus senhores quanto de seus companheiros igualmente escravos. Emocionante é o depoimento da militante e socióloga Azelene Kaingáng, ao mostrar como as indígenas são capazes de se impor sobre papéis sexuais, espaços políticos e de se fazerem representativas. A autora contanos sobre as tradições, mudanças de comportamento e como as mulheres agem frente à luta por reconhecimento social. O texto é inovador porque nos informa como muitas mulheres enfrentam até hoje os costumes e a violência com a qual são tratadas no interior de suas comunidades.

Cristina Sheibe Wolf desnaturaliza estereótipos em torno de mulheres que participaram de guerras, revoltas e guerrilhas, atividade vista exclusivamente como sendo dos homens. Traz à cena nomes consagrados, como Maria Quitéria Anita Garibaldi, Ana Nery, entre outras, representativos em contextos de guerras. Suas reflexões perpassam pelas lutas pela Independência do Brasil à guerrilha contra a ditadura militar, pela Guerra do Paraguai, o cangaço e a Segunda Guerra Mundial, dando visibilidade à ałuação de mulheres que combateram nas guerras.

Tânia Regina de Luca enfatiza os diferentes momentos nos quais o assunto mulheres aparece na imprensa, acompanhando as conquistas e a igualdade formal de direitos políticos. Também questiona acerca de um notável desiquilíbrio entre a presença de figuras públicas masculinas e femininas no noticiário, assim como certos estereótipos em torno de mulheres que adentraram na arena do poder. Carla Bassanezi Pinsky contextualiza as mudanças acerca dos modelos rígidos e as representações imagéticas em torno da figura feminina, contribuindo com enfoques inovadores quanto à percepção de determinadas expressões de época por meio das quais muitas mulheres foram enquadradas e/ou estereotipadas. A autora mostra-se competente quanto à visualização de um cenário de imagens e à sua complexidade no processo da história.

É inegável que as reflexões contidas nesses textos instituem certos princípios formadores de uma nova teoria e práticas de se pensar os diferentes espaços das mulheres brasileiras, contribuindo para o reconhecimento de nossa própria história enquanto mulher. A obra é um marco na história das mulheres no Brasil, pois aponta, no mínimo, para a reavaliação de concepções e formas múltiplas de discriminação, instigando o/ a leitor/a a refletir e a questionar certos tabus e valores que permanecem em torno das mulheres nos últimos dois séculos. Coloca ainda em xeque certas posturas excludentes acerca do feminino, reflexão esta que vem ao encontro da ideia de que não se devem abandonar as bandeiras de luta, embora estas já não se traduzam com base em verdades incontestes, e sim em verdades verossímeis no que diz respeito às novas práticas e discursos das mulheres em diversos âmbitos da sociedade vigente.

Gilmária Salviano Ramos Universidade Federal de Santa Catarina 